\title{
Familial Intracranial Aneurysms: Recurrence Risk and Accidental Aggregation Study
}

\author{
Jean Mathieu, Gilles Hébert, Louis Pérusse, Claude Prévost, Léo Cantin, \\ Jean-Marie Bouchard and Marc DeBraekeleer
}

\begin{abstract}
Background: The Saguenay-Lac-Saint-Jean (SLSJ) region is a geographically isolated area (population 285,955) located in the Northeastern part of the Province of Quebec, Canada. Using a populationbased register, the genealogical reconstruction of 502 individuals with ruptured intracranial aneurysm (RIA) showed a familial aggregation (the presence of aneurysm in two or more first- to third-degree relatives) for $144(28.7 \%)$ of them; this proportion is much higher than reported elsewhere. Objective: In order to assess the genetic predisposition to RIA in the SLSJ population, the objective of the present study is to compare familial and non-familial cases and to provide an estimate of the recurrence risk ratio for siblings. Results: The age at the time of rupture, the number of intracranial aneurysms for each patient and the location of RIAs were not statistically different in the familial versus the non-familial group. Of the 3449 siblings, $20(0.58 \%)$ had suffered a RIA. The recurrence risk ratio calculated for siblings (defined as the risk of disease among siblings divided by the estimated population prevalence) is 1.6 (CI 95\% $1.0-2.4)$. In other respects, we observed very large kinships in the SLSJ population, with an average number of siblings of 7.2 (SD \pm 3.4 ), ranging from 0 to 17 individuals. With such large families and on the basis of chance alone, we expected $31.3 \%$ of the patients to have at least one first- to third-degree relative with RIA. Conclusion: These data show that siblings of patients with RIA in the SLSJ population have a greater risk of RIA than the general population. Nevertheless, the largest part of the familial occurrence observed in the SLSJ region can be explained by accidental aggregation, due to large kinships. We propose that, in this population, an underlying genetic predisposition must be suspected only when three or more cases of RIA are identified among first- to third-degree relatives.
\end{abstract}

RÉSUMÉ: Les anévrysmes intracrâniens familiaux: étude du risque de récurrence et de l'agrégation accidentelle. Introduction: Le Saguenay-Lac-Saint-Jean est une région géographiquement isolée de 285,955 habitants, localisée au nord-est de la Province de Québec. La reconstruction généalogique réalisée à partir du fichier de population du Saguenay Institut Interaniversitaire de recherches sur les populations (IREP) a démontré que, parmi les 502 patients porteurs d'un anévrysme intracrânien rupturé (AIR), $144(28,7 \%)$ montraient des liens d'apparentement au le, au $2 e$ ou au 3e degré avec un autre sujet atteint. Cette proportion est beaucoup plus élevée qu'ailleurs. Objectif: Ce projet vise à vérifier l'hypothèse d'une étiologie génétique dans la genèse des AIR au SLSJ en comparant les cas familiaux et non familiaux et en estimant le risque de récurrence dans la fratrie. Résultats: Il n'y a pas de différence significative entre l'âge à la rupture, le nombre d'AI chez chaque patient et la localisation des AIR entre le groupe des cas familiaux et des cas non-familiaux. Parmi les 3449 frères et soeurs des patients, $20(0,58 \%)$ ont présenté une rupture d'AI. Le ratio du risque de récurrence dans la fratrie, défini comme le risque de rupture d'AI parmi les individus de la fratrie divisé par le risque estimé de rupture d'AI dans la population générale, est de 1,6 (IC 95\% 1,0-2,4). Cependant, nous observons des familles de taille très importante dans la population saguenéenne; la taille moyenne de la fratrie des patients porteurs d'un AIR étant de 7.2 individus (ET \pm 3.4 , étendue: $0-17$ individus). Compte tenu de cette taille importante des familles saguenéennes, la chance de retrouver fortuitement un autre individu avec rupture d'AI apparenté au le, $2 \mathrm{e}$ ou $3 \mathrm{e}$ degré avec un patient est de 31,3\%. Conclusion: Ces données montrent que les individus appartenant à la fratrie d'un patient porteur d'un AIR ont un plus grand risque de rupture d'AI que la population générale. Cependant, la majeure partie des cas dits familiaux rapportés au SLSJ sont dus à une agrégation accidentelle en raison de taille importante des familles saguenéennes. Dans cette population, nous proposons donc qu'une prédisposition génétique soit suspectée lorsqu'il y a trois (3) individus ou plus avec rupture d'AI parmi les parents du le, 2e ou 3e degré.

Can. J. Neurol. Sci. 1997; 24: 326-331

The Saguenay-Lac-Saint-Jean (SLSJ) region is a geographically isolated area located in the Northeastern part of the Province of Quebec. The region was opened to white settlement in 1838 and most of its population originated from the nearby Charlevoix County. The population grew quickly, first by immigration then naturally. From a few thousands in its early
From the Unité de recherche clinique, Complexe Hospitalier de la Sagamie, Chicoutimi, (J.M., C.P., L.C., M.D.); Groupe de recherche ECOBES, Cegep de Jonquière, Jonqujère, (G.H.); Université du Québec à Chicoutimi, Chicoutimi, (J.M., M.D.); Université Laval, Québec, (L.P., J.-M.B); Hôpital Enfant-Jésus, Québec, Québec, (J.-M.B.).

RECEIVED JANUARY 28, 1997. ACCEPTED IN FINAL FORM JUNE 18, 1997.

Reprint requests to: Dr. Jean Mathieu, Unité de recherche clinique, Complexe Hospitalier de la Sagamic, 305 Saint-Vallier, Chicoutimi, Québec, Canada G7H 5H6 
decades, the population rose to 50,000 in 1911 to attain 285,955 in 1991 .

Neurologists and neurosurgeons working in the SLSJ region identified numerous cases of familial intracranial aneurysms (IA) in the last decade. The familial occurrence of IA is defined by the presence of such IA in two or more first- to third-degree family members.' Using the population-based register of the SLSJ population (IREP), the genealogical reconstruction of 502 individuals with ruptured intracranial aneurysm (RIA) revealed a familial aggregation for 144 of them $(28.7 \%){ }^{2}$ The hypothesis of a new genetic disorder was put forward since several dominant and recessive autosomal disorders have a high prevalence in the SLSJ population..$^{3-5} \mathrm{~A}$ founder effect in the establishment of the French-Canadian population was suggested in this area. ${ }^{6}$

The purpose of the present study is to analyse the clinical characteristics of patients with familial vs. non-familial RIA and to assess the recurrence risk for siblings. We also propose a new methodological approach to analyse accidental familial aggregation based on cumulative rates of RIA.

\section{Methods}

\section{Patients}

Case ascertainment has been previously described in an epidemiological study of RIA in the SLSJ region. ${ }^{7}$ Briefly, all the medical records of patients with the diagnosis of aneurysmal subarachnoid hemorrhage, during the period 1965 to 1993, were reviewed in each hospital in the SLSJ region and at the EnfantJésus Hospital in Québec City. Diagnosis of RIA was made by angiography $(11.7 \%)$, surgery $(2.4 \%)$, post-mortem examination (13.8\%) or a combination of several of these procedures $(72.1 \%)$. A total of 502 patients with RIA were identified. Cases of spontaneous subarachnoid hemorrhage (SAH) without proof of a RIA were excluded from the present study. Data on age at rupture, number of IA, location and size of RIA were also abstracted from medical records.

\section{Genealogical Reconstruction}

The genealogies of these 502 patients with RIA were automatically reconstructed using the SLSJ population register developed and maintained at IREP (University of Quebec at Chicoutimi). This population register contains more than 900,000 birth, marriage, and death certificates related to the French Catholic population of SLSJ from 1838 to 1986. Complete methodology concerning these reconstructions was described elsewhere. ${ }^{2}$

\section{Cumulative Risks and Cumulative Rates}

The cumulative risk is defined as the risk an individual would have of developing the disease in question during a certain age period if no other causes of death were in operation. ${ }^{8}$ The cumulative rate is the sum over each year of age of the agespecific incidence rates taken from birth to a certain age. The cumulative rate can be interpreted as an approximation to the cumulative risk. ${ }^{8}$ We derived cumulative rates and risk of RIA in SLSJ population from the age-specific incidence rates of RIA reported in our previous epidemiological study of RIA in this population from 1973 to 1992.7 The cumulative risk of intracranial aneurysmal rupture in the SLSJ population up to age 20 is $0.01 \%$, up to age 45 is $0.22 \%$ and up to age 70 is $0.69 \%$.

\section{Identification of Relatives}

Using the SLSJ population register, we identified all siblings of each patient with RIA as well as all siblings of their parents. For the purpose of the recurrence risk calculation, we kept only the siblings who survived the age of 10 . The recurrence risk ratio is defined as the observed cases of RIA among siblings divided by the expected cases of RIA among a reference population of the same age and size. This corresponds to the lambda $\left(\lambda_{s}\right)$ coefficient used in genetic studies of complex traits. ${ }^{9}$ The expected number of recurrences in the reference population was calculated by using cumulative rates of RIA in SLSJ population.

\section{Accidental Familial Aggregation}

Accidental familial aggregation was defined as the probability that a patient admitted with a RIA had at least a first to third degree relative with previous RIA by chance alone ${ }^{1,10}$ For the estimation of accidental familial aggregation, we propose a method based on the specific cumulative risks (or rate) of RIA of each generation. The calculation of the total number of relatives in each generation is illustrated in Figure 1. Based on the

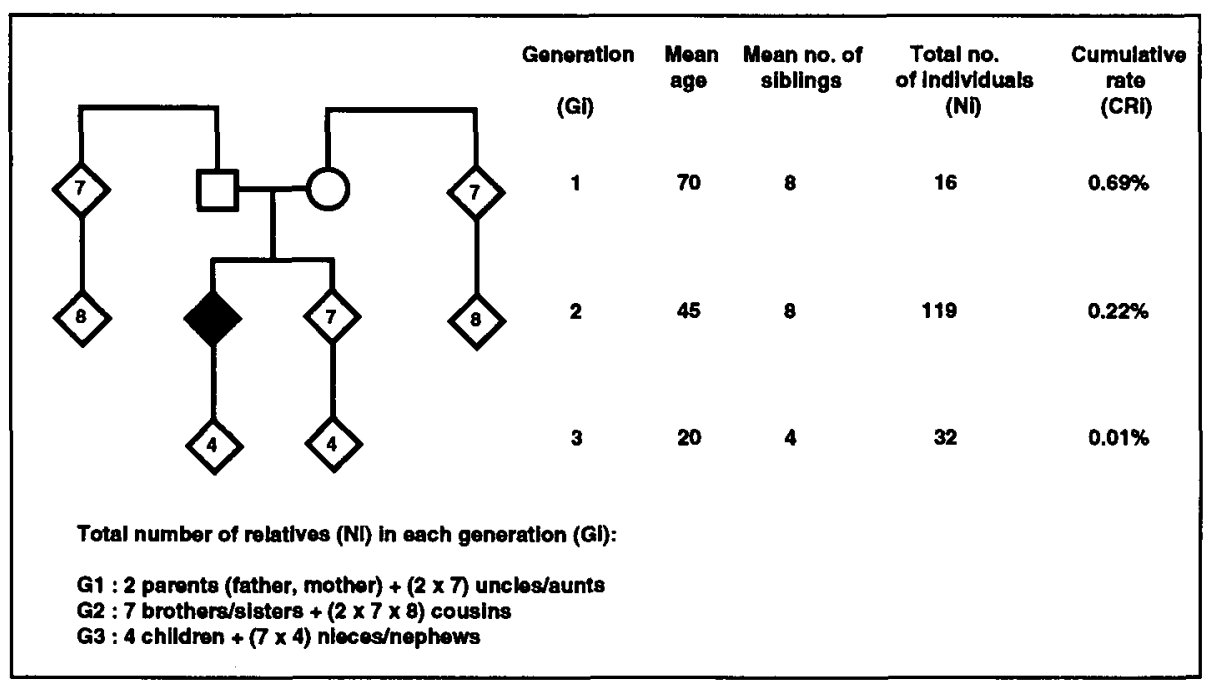

Figure 1: Total number of relatives in each generation used for calculation of accidental aggregation of RIA by the cumulative risks method. 
age at time of rupture observed in this population (46.4 years), we attributed the following mean age for each generation: 70 years in generation 1, 45 years in generation 2 (propositus generation) and 20 years in generation 3 . We assumed that the distribution of affected relatives of an individual with RIA follows the Poisson law with a parameter $t$. The parameter $t$ is the summation $(\Sigma)$ of the total number of individuals in each generation (Ni) multiplied by their generation-specific cumulative risk (CRi). The probability (P) to observe an exact number ( $\mathrm{x}$ ) of individuals with RIA who are first to third degree relatives is described by:

$$
P(x)=\frac{e^{-t} t^{x}}{x !} \quad t=\sum(N i C R i)
$$

\section{RESULTS}

\section{Description of Pedigrees of Familial Cases}

Using the population-based register of the SLSJ population (IREP), the genealogical reconstruction of 502 individuals with RIA revealed a familial aggregation for 144 of them $(28.7 \%){ }^{2}$ These 144 cases are identified as familial cases and the others $(\mathrm{N}=358)$ as non-familial cases. The familial cases are distributed in 63 families and the pedigrees are illustrated in Figure 2. Of the 63 families, the great majority $(76.2 \%)$ included only two affected members; 12 families (19\%) had 3 affected members and 3 families $(4.8 \%)$ included 4 affected members. In this population, we did not observe families with 5 or more affected individuals, neither twin pairs. In 5 pedigrees, individuals had affected relatives on both paternal and maternal side.

Among the 502 individuals with RIA, we found no case of polycystic kidney disease, coarctation of the aorta, EhlersDanlos syndrome, Marfan's syndrome, collagen deficiency states or fibromuscular dysplasia.

\section{Comparison of Familial and Non-familial Cases}

The age at time of rupture, the male to female ratio, the multiplicity of IA and the site of RIA were similar in familial $(\mathrm{N}=144)$ and non-familial $(\mathrm{N}=358)$ cases (Table 1). We found more giant aneurysms $(>2.5 \mathrm{~cm})$ and less small aneurysms $(<1.0 \mathrm{~cm})$ in the familial group than in the nonfamilial group $(p=0.0002)$.

\section{Recurrence Rate Among Siblings}

The average number of siblings of patients with RIA is 7.2 $(\mathrm{SD} \pm 3.4$ ), ranging from 0 to 17 individuals. Of the 3449 siblings, $20(0.58 \%)$ had suffered a RIA. Using the cumulative risks of RIA from the SLSJ population with the same age distribution, $12.5(0.36 \%)$ cases of RIA were expected. Therefore, the $\lambda_{\mathrm{s}}$ coefficient or the recurrence risk ratio for siblings is 1.6 (CI $95 \% 1.0-2.4)$.

\section{Accidental familial aggregation}

Using the methodological approach based on cumulative rates of RIA as described in methods, the probabilities to observe in a family $1,2,3,4$ or $\geq 5$ individuals with a RIA are respectively $68.7 \%, 25.8 \%, 4.8 \%, 0.6 \%$ and $0.1 \%$. Therefore, we expected that, based on chance alone, $31.3 \%(1-68.7 \%)$ of the patients would have at least one first- to third-degree relative with RIA. The expected distribution based on accidental aggre- gation of number of families with respectively $2,3,4$ and $\geq 5$ affected relatives is compared with the observed one in the SLSJ population (Table 2) and do not show any significant difference.

\section{Discussion}

Numerous case reports describe families with two or more patients having RIA or unruptured IA. ${ }^{1,11,12}$ In a series of 485 patients with RIA, Norrgard et al. ${ }^{13}$ identified 32 patients $(6.7 \%)$ with a first- to third-degree relative who had a RIA. In a series of 1150 aneurysmal subarachnoid hemorrhage (SAH) patients from eastern Finland, Ronkainen et al. ${ }^{14}$ found 113 patients (10\%) with a proven familial occurrence of aneurysmal SAH. The proportion of familial RIA observed in the SLSJ population $(28.7 \%)$ is much higher than reported anywhere else and prompted us to investigate whether some RIA were genetically determined in this population.

IA are known to be part of the clinical picture of several hereditary disorders such as Marfan syndrome, Ehlers-Danlos type IV syndrome and adult polykystic kidney disease. Whether a genetic predisposition is involved in the genesis of IA without being associated with one of these disorders remains to be proven. Schievink et al. ${ }^{12}$ reported a segregation analysis based on 73 of the 238 families with multiple affected individuals described in the literature. Their analysis revealed different patterns of inheritance, with autosomal dominant and recessive transmissions giving the best-fitting models. Based on angiography of asymptomatic at-risk siblings, Alberts et al. ${ }^{15}$ proposed a pattern consistent with an autosomal dominant trait in a selected series of sibship. The occurrence of IA at the same site or mirror site in sibling pairs, the concordance in identical twins and the association of IAs with genetically transmitted disorders are three factors which suggest a genetic basis for familial IA.' Schievink et al. ${ }^{16}$ suggested that the heterozygous and homozygous $\alpha 1$-antitrypsin deficiency states are genetic risk factors for the development of IAs. Our previous results of the genealogic reconstruction of 533 individuals with RIA and unruptured IA showed that $29.8 \%$ of the individuals were related up to the third-degree level, compared to $18.6 \%$ among the controls. ${ }^{2} \mathrm{We}$ also observed a decrease of incidence of familial IA between the first, second and third degrees of relationship. ${ }^{2}$ These results suggest that some IA are genetically determined in the SLSJ population and that one or several dominant genes are segregating in this population. Whether the genes are major with reduced penetrance remains to be elucidated. In the present study, using a different methodological approach in the same population, we estimated that siblings of patients with RIA have a 1.6 times greater risk of RIA than the general population. The recurrence rate among siblings observed in this study $(0.58 \%)$ is similar to the results of Bromberg et al. ${ }^{17}$ who found 9 definite recurrences among 1267 first degree relatives $(0.71 \%)$ and showed that the first degree relatives of patients with SAH have a two to six times greater risk of SAH than the general population. These results also support a genetic basis to the development of some IA.

Our study shows a higher proportion of giant aneurysms in the familial group compared to the non-familial group without any known reason. Although the size of a RIA is not always reported in the literature, Lozano et al. ${ }^{11}$ found that familial aneurysms rupture at a smaller size (mean diameter $10.5 \mathrm{~mm}$ ) 


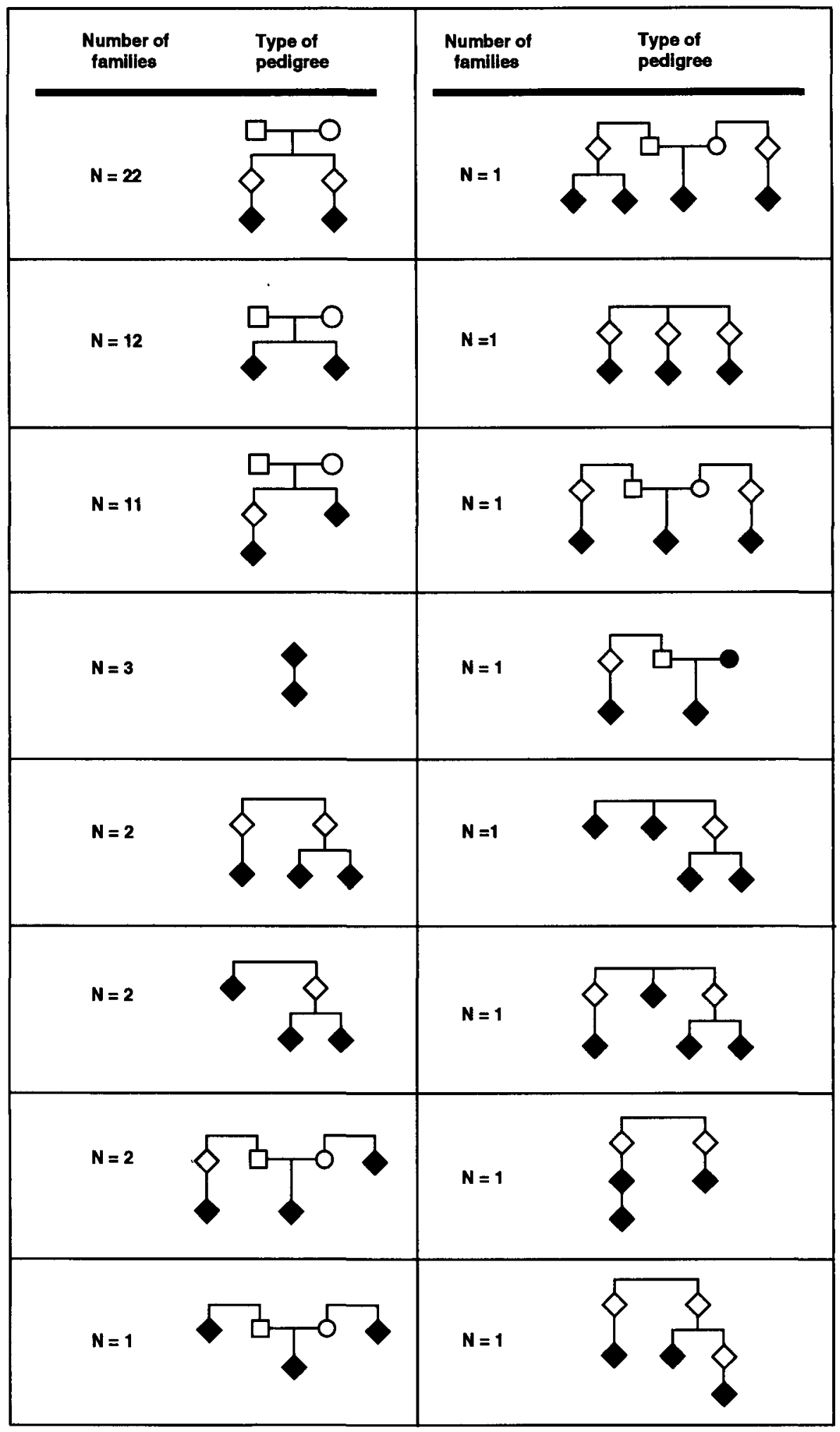

Figure 2: Pedigrees of the 63 families from SLSJ region with more than one case of RIA. 
Table 1: Comparative data between familial and non-familial intracranial aneurysms.

\begin{tabular}{|c|c|c|c|c|}
\hline & & $\begin{array}{c}\text { Familial } \\
\text { cases } \\
\mathrm{N}=144\end{array}$ & $\begin{array}{c}\text { Non fam lilial } \\
\text { cases } \\
\text { Nm358 }\end{array}$ & \\
\hline Age et rupture & Mean $\pm S D$ & $47.4 \pm 13.0$ & $46.0 \pm 13.2$ & t-test $0=0.2721$ \\
\hline Sex ratlo & $(M / F)$ & 0.60 & 0.86 & $\chi^{2} \quad p=0.7$ \\
\hline Multiple aneurysms & $(\%)$ & 26.8 & 21.6 & $\chi^{2} p=0.39$ \\
\hline Location of IA & (\%) & & & \\
\hline Anterior cerebral & & 31.7 & 38.0 & \\
\hline Intemal carotid & & 27.5 & 30.0 & \\
\hline Middle cerebral & & 35.2 & 26.1 & \\
\hline Others & & 5.6 & 5.9 & $\chi^{2} p=0.16$ \\
\hline Size of IA & (\%) & & & \\
\hline$<1.0 \mathrm{~cm}$ & & 33.3 & 42.2 & \\
\hline $1.0-2.5 \mathrm{~cm}$ & & 54.9 & 56.2 & \\
\hline$>2.5 \mathrm{~cm}$ & & 11.8 & 1.6 & $\chi^{2} \mathrm{p}=0.0002$ \\
\hline
\end{tabular}

Table 2: Observed and expected distribution of number of families with affected relatives.

\begin{tabular}{|c|c|c|c|}
\hline \multirow{2}{*}{$\begin{array}{l}\text { Number of } \\
\text { Affected } \\
\text { Members }\end{array}$} & \multicolumn{2}{|c|}{$\begin{array}{l}\text { Observed } \\
\text { no of familles }\end{array}$} & \multirow{2}{*}{$\begin{array}{c}\text { Expected } \\
\text { no of familles } \\
\%\end{array}$} \\
\hline & $N$ & $\%$ & \\
\hline 2 & 48 & 76.2 & 82.4 \\
\hline 3 & 12 & 19.0 & 15.4 \\
\hline 4 & 3 & 4.8 & 1.9 \\
\hline$\geq 5$ & 0 & 0.0 & 0.3 \\
\hline Total & 63 & 100.0 & 100.0 \\
\hline
\end{tabular}

$\chi^{2}=1.34, \rho=0.5$

and suggested a more significant underlying vascular defect in familial cases leading to earlier rupture. Otherwise, the main clinical characteristics of familial IA are a younger age at rupture (about 42 years) than in non-familial IAs (about 50 years) $)^{1,11,13}$ and a lower prevalence of anterior communicating artery aneurysms in familial cases than in sporadic cases. ${ }^{11}$ In the present series, the age at time of rupture is similar in familial (47 years) and non-familial cases (46 years). The proportion of IA at anterior cerebral artery site is similar in our familial cases $(32 \%)$ than in non-familial aneurysms $(38 \%)$. Therefore, we did not observe a lower occurrence of anterior cerebral aneurysms or a tendency to rupture at a smaller size or at a younger age as reported in other familial series. These results are in accordance with our previous epidemiological study where no significant increase of age-specific incidence rates of RIA in the SLSJ population was found?

In other respects, it seems likely that families with only two affected members may represent accidental or fortuitous aggregation. ${ }^{1}$ Dippel et al. ${ }^{10}$ proposed a method of calculation of accidental familial aggregation based on the risk of harboring an unruptured IA and the annual rate of rupture derived from literature. In the present study, the average size of the sibship with at least one member carrying a RIA is 8.2 persons. By taking a mean sibship size of 8 persons and a mean age of 40 and using the method proposed by Dippel, the proportion of familial cases explained by fortuitous aggregation would be $48.3 \%$. We proposed here to use generation-specific cumulative rates of RIA to obtain a more accurate estimation of the proportion of fortuitous familial cases. The cumulative rate of RIA for a certain age period is a good approximation of the risk of harboring an unruptured IA and of the annual risk of rupture for the same age period. Based on this method, we expected $31.3 \%$ of the patients to have at least one first- to third-degree relative with RIA only by chance. This estimated proportion of familial cases is very close to the proportion observed in the present study $(28.7 \%)$. The largest part of the familial occurrence observed in the SLSJ region can then be explained by accidental aggregation. Because of the large kinships observed in the SLSJ population, we propose that, in this population, an underlying genetic predisposition must be suspected only when three or more cases of RIA are identified among first- to third-degree relatives.

Schievink ${ }^{18}$ recently reviewed the genetic aspects of IAs and proposed screening guidances for asymptomatic relatives. Screening for familial IAs is generally recommended for firstdegree relatives in families with two or more affected members. These generic guidances should occasionally be adjusted in accordance with the demographic and the epidemiological characteristics of a specific population. Therefore, in the SLSJ population, we recommend the screening of asymptomatic first-degree relatives in families with two affected siblings; otherwise, screening should be restricted to families with three or more affected cases among first- to third-degree relatives.

\section{ACKNOWLEDGEMENT}

This work was supported by research grants \#921017-102 from the Fonds de Recherche en Santé du Québec and from the Fondation de l'Université du Québec à Chicoutimi.

\section{REFERENCES}

1. ter Berg HW, Dippel DW, Limburg M, Schievink WI, van Gijn J. Familial Intracranial aneurysms. A review. Stroke 1992; 23: 1024-1030.

2. De Braekeleer M, Cantin L, Bouchard JM, Pérusse L, Mathieu J. A study of inbreeding and kinship in intracranial aneurysms in the Saguenay-Lac-Saint-Jean region (Quebec, Canada). Ann Hum Genet 1996; 60: 99-104.

3. De Braekeleer M, Larochelle J. Genetic epidemiology of hereditary tyrosinemia in Quebec and Saguenay-Lac-Saint-Jean. Am J Hum Genet 1990; 47: 302-307.

4. Mathieu J, De Braekeleer M, Prévost C. Genealogical reconstruction of myotonic dystrophy in the Saguenay-Lac-Saint-Jean area (Quebec, Canada). Neurology 1990; 40: 839-842.

5. De Braekeleer M. Hereditary disorders in Saguenay-Lac-Saint-Jean (Quebec, Canada). Hum Hered 1991; 41: 141-146.

6. Rozen R, De Braekeleer M, Daigneault J, et al. Cystic fibrosis mutations in French Canadians: three CFTR mutations are relatively frequent in a Quebec population with an elevated incidence of cystic fibrosis. Am J Hum Genet 1992; 42: 360-364.

7. Mathieu J, Pérusse L, Allard P, et al. Epidemiological study of ruptured intracranial aneurysms in the Saguenay-Lac-SaintJean region (Quebec, Canada). Can J Neurol Sci 1996; 23: 184-188.

8. Day N. Cumulative rate and cumulative risk. In: Muir C, Waterhouse J, Mack T, Powell J, Whelan S, eds. Cancer Incidence in Five Continents, Volume V. 88th ed. Lyon: IARC Scientific Publications, 1987: 787-789. 
9. Risch N. Linkage stategies for genetically complex traits. II. The power of affected relative pairs. Am J Hum Genet 1990; 46: 229241.

10. Dippel DW, ter Berg JW, Habbema JD. Screening for unruptured familial intracranial aneurysms. A decision analysis. Acta Neurol Scand 1992; 86: 3814-3819.

11. Lozano A, Leblanc R. Familial intracranial aneurysms. J Neurosurg 1987; 66: 522-528.

12. Schievink WI, Schaid DJ, Rogers HM, Piepgras DG, Michels VV. On the inheritance of intracranial aneurysms. Stroke 1994; 25 : 2028-2037.

13. Norrgard Ö, Ängquist K-A, Fodstad H, Forsell A, Lindberg M. Intracranial aneurysms and heredity. Neurosurgery 1987; 20 : 236-239.
14. Ronkainen A, Hernesniemi J, Ryynänen M. Familial subarachnoid hemorrhage in East Finland, 1977-1990. Neurosurgery 1993; 33: 787-797.

15. Alberts MJ, Quinones A, Graffagnino C, Friedman A, Roses AD. Risk of intracranial aneurysms in families with subarachnoid hemorrhage. Can J Neurol Sci 1995; 22: 121-125.

16. Schievink WI, Katzmann JA, Piepgras DG, Schaid DJ. Alpha-1antitrypsin phenotypes among patients with intracranial aneurysms. J Neurosurg 1996; 84: 781-784.

17. Bromberg JEC, Rinkel GJE, Algra A, van Gijn J. Subarachnoid hemorrhage in first and second degree relatives of patients with subarachnoid hemorrhage. J Neurol 1994; 241: S91.

18. Schievink WI. Genetics of intracranial aneurysms. Neurosurgery 1997; 40: 651-663. 